Article

\title{
Corporate Perspectives on Responsibility and Sustainability in the Food System: A (Food) Communicative-Constructivist Viewpoint
}

\author{
Tina Bartelmeß * (1) and Jasmin Godemann \\ Department of Communication and Engagement in Agricultural, Nutritional and Environmental Sciences, \\ Justus-Liebig-University Giessen, 35390 Giessen, Germany; Jasmin.Godemann@fb09.uni-giessen.de \\ * Correspondence: Tina.Bartelmess@fb09.uni-giessen.de; Tel.: +49-641-99-39345
}

Received: 31 January 2020; Accepted: 4 March 2020; Published: 6 March 2020

\begin{abstract}
This study examines how corporations in the German food industry understand and perceive communication as a corporate social responsibility (CSR) dimension, how they communicate about food-related sustainability, and how this corporate food communication can lead to sustainability-oriented change in action-guiding institutions. This study takes a communicative-constructivist viewpoint that does not focus on the extent to which the communicated corresponds to the actual action but rather on how communication and communicatively constructed institutions can shape, influence, or constitute the action. A comparative qualitative case study approach reveals how two deviant cases within the producing and processing food industry assume responsibility through food communication and identifies five underlying roles of communication that, in their case-specific variations yield in two different conceptualizations of perceiving responsibility through communication. The analysis and interpretation of data, in the reference frame of communicative institutionalism, outline promising prospects on how corporate food communication can contribute to institutional changes that guide decisions and actions for sustainable development of the food system. Furthermore, the findings highlight food quality as a relevant communication resource for food-related discussions about sustainability that cross systems in the context of the food system and transforms an institution in such a way that it now also refers to aspects of sustainability.
\end{abstract}

Keywords: corporate social responsibility; food communication; sustainable food quality; communicative institutionalism; comparative qualitative case study

\section{Introduction}

Sustainable development of the food system profoundly challenges society by creating pressure for action through widespread social debate about food and attributions of responsibility vis-à-vis various actors of society. The food system consists of a complex of institutions, organizations, actors, and actions that takes place across the multiple contexts of food production, distribution, exchange, consumption, post consumption, and food policy regulations [1,2]. Public concerns regarding questions relating to environmental, social, and individual challenges of food, result in identifying especially food production and consumption as a multifaceted sustainability concern. Responsibility is particularly ascribed to industry so that it balances economic, ecological, and social aspects in the value chain [3]. Due to the socio-political demand of corporate engagement in corporate social responsibility (CSR), producing and processing food corporations as central actors of the food system have to take a stance on sustainability and have to report on their efforts to tackle challenges such as child labor, overweight, or deforestation. Through this so-called CSR communication, they participate in various social sustainability discourses where they express their concern and commitment to sustainable development. In the food industry, 
CSR and related communication always pertains to aspects of food and its production, and thus can be understood as sustainability-related food communication [4]. Within sustainability-related corporate food communication, corporations develop and communicate their own understandings of how a sustainable food system could be achieved. From a communicative-constructivist viewpoint, CSR communication is seen as a complex process of meaning making and communication in turn is seen as shaping, influencing, or constituting the CSR actions [5]. With reference to communicative institutional theory, it is assumed that by discursively engaging in social understanding processes, corporations construct specific understandings of institutions that guide responsibility- and sustainability-oriented action. Depending on the predominant interpretative resources in the diverse discursive spaces, distinct meanings of how to behave responsibly and sustainably are constructed [6,7]. In this way, those created, prevailing different understandings of sustainability, result in various ways of assuming responsibility for a sustainable development of the food system and specify particular responsibility fields, objects and actions that are regarded as essential by the different actors. Through communicative engagement in societal discourses, different understandings of sustainability by various actors circulate, interfaces for mutual understanding are found, and various perspectives on sustainability can be integrated.

Thus, communication takes on a crucial role in the social processes of understanding relating a transformation to a more sustainable food system. Referring to social constructivism, it is through communication that social phenomena, for example, responsibility or sustainability, are commonly constructed [8] and institutions as common cognitive understandings guiding actions of individuals and organizations are maintained, created, or disrupted $[6,7,9,10]$. Through the communication of different understandings relating to food, responsibility and sustainability become institutionalized and, in turn, guide the actions of different people and organizations in the food system.

This study draws on the theory of communicative institutionalism $[7,10]$, to show how corporations, through food communication, engage in discourses surrounding the overriding theme of a sustainable food system. It demonstrates how corporate food communication contributes to the construction of responsibility within these discourses and illustrates how a sustainability-oriented institution of food quality is discursively reconstructed through social communication processes that involve disparate social perspectives on sustainability.

We apply a comparative case study approach to investigate how corporations in the food industry understand and perceive food communication as part of their responsibility and how corporate food communication contributes to the maintenance, creation, or disruption of institutions, in turn, guiding future actions and interactions relevant to sustainable development of the food system. Our study shows that the two investigated food industry corporations have a similar understanding of the responsibility dimension of communication but perceive it in different ways which results in varying roles of communication with different implications for institutionalization. Our findings reveal that food quality, as the dominant responsibility object and as an action-guiding institution, has undergone a fundamental extension of meaning in the context of sustainability, opening up to integrate different people-centered perspectives and requirements for sustainability in the food system.

The paper is structured as follows: First, we discuss the theoretical context on which we draw and in which our case study is embedded; next, we present our research design and cases, followed by our analysis and discussion; finally, we end with our conclusions, where we show how our findings contribute to sustainability-centered food studies, discuss limitations of our study and put forward several propositions for future research.

\section{Embedding Corporate Responsibility and Food Communication in Institutional Theory}

\subsection{Responsibilities and Communication of Food Industry Corporations}

Corporations are faced with multiple sustainability challenges to organize food production and processing and respond to these challenges mainly under the heading of CSR. CSR is understood to be the responsibility of business to develop strategies that engage in sustainability which is a 
"constantly moving target" that is shaped by socio-political expectations, technological possibilities, and public concerns raised by the media [11] (p. 491). In the food industry, CSR is crucial due to the tension within corporations between aiming for economic efficiency in production and, at the same time, ensuring food quality and sustainability [12]. Thus, CSR communication can be seen as one field of sustainability communication that is characterized as an "ever-changing and dynamic corporate response to different societal challenges and information needs and the expectations of various stakeholders" [13] (p. 166). There is an emerging area of research concerned with individual and organizational meaning-making [14], as CSR communication can reveal implicit, and often even explicit, attempts to redefine what "socially responsible" means $[15,16]$. However, the majority of CSR studies adopt a strategic view on communication and focus on instrumental purposes and effectiveness of the organizational communication about its CSR activities and results $[5,17]$, but this perspective offers "insufficient understanding of the complex dynamics around CSR" [18] (p. 691).

From a food communication perspective, CSR communication of food corporations, up to now, have mainly been considered to be marketing communication with the aim to transfer nutritional information relating to the health value of products to consumers. From a meaning-centered perspective, the content of CSR communication can include different aspects relating to sustainable food and its production and processing [19]. Corporations need to explicitly state to society what "sustainable food" perspective they have (food values, beliefs, assumptions, perceptions, and conceptions) and they need to inform society about their food-related CSR programs; actualize, measure, and record their programs; and justify related corporate actions. Finally, they have to identify and address social concerns and issues that relate to corporate actions and keep society informed of how those issues are tackled. By assuming a broad understanding of food as not just a physiological necessity but rather a "total social fact" [20] interrelated with all aspects of life, CSR communication of food corporations can be seen as one manifestation of sustainability-related food communication. Due to CSR communication, corporations in the food industry talk about food issues, construct understandings of sustainable (unsustainable, healthy etc.) food or food production, and (re)produce their corporate identities, boundaries, and production cultures with respect to their responsibility for sustainable development [21]. Through organizing food production, processing, and related corporate communication, corporate food communication is part of the societal discursive struggle over the meaning of sustainable food, sustainable food production, and a sustainable food system.

Communication and business ethics scholars note that the diversity of legitimate social perspectives makes it necessary to ensure engagement of corporations in broader social understanding processes in order to recognize that society has a shared agenda of living in a sustainable world [22], as well as creating shared value and meaning [23]. Instead of communicating CSR messages to critical receivers, scholars conceive CSR communication from a meaning-centered perspective more as communication "about" sustainability with the potential of resulting in communication "for" sustainability by producing shared visions and institutions that characterize sustainable food and food actions in society [24]. However, research on communication as a CSR dimension is scarce and there are no empirical descriptions of how corporations perceive responsibility through communication or theoretical insights of how corporate food communication can contribute to sustainable development.

\subsection{Corporate Food Communication in Institutional Theory Perspectives}

The strands of communicative institutionalism theory helps to concretize the potential of CSR-related food communication for sustainable development. Communicative institutionalism puts communication and discourse forefront and discursively views emerged, produced, and reproduced institutions as constitutive for individual and organizational actions. Communicative institutionalists began to further develop an approach to comprehend the process of social construction that underlies institutional construction by providing discourse on theoretical and methodological concepts $[10,25]$. A key assumption of communicative institutionalism is that any common cognitive understanding that shapes the basis of institutions is constantly produced and reproduced through communication [9]. 
Scholars argue that institutions are constituted by the structured collections of texts that exist in particular fields $[7,26]$ and these produce the institutions that shape individual and organizational understandings and actions [10]. By taking into account the social context where these texts frequently circulate [27], we draw on the theoretical concept of "issue-based fields" [7]. In line with the cognitive perspective, issue-based fields and inherent social discourses are treated as an interpretative environment that functions as a social context and for considering multiple perspectives to negotiate the meanings that underpin decisions and actions [27] (p. 338). According to Hoffman [7] (p. 352) " $a$ field is formed around the issues that become important to the interest and objectives of a specific collective of organizations". Thus, this concept helps to provide an empirical platform for understanding corporate food communication across multiple social interactions and audiences and opens up an analytical focus on the interrelation of sustainability-related food communication with the communicative maintenance, creation, or disruption of institutions relevant to deciding and acting sustainably [9,28]. Moreover, the concept of" institutional entrepreneurs" emphasizes the role of social actors and organizations in shaping the institutions that legitimate the practices and actions that constitute a field [29].

We recognize communication as a key instrument in institutionalization processes for sustainable development in the issue-based fields of sustainable food and identify the relevant fields and different roles of communication in perceiving communication as a corporate responsibility dimension. Furthermore, we discuss how different conceptualizations of communication as a responsibility dimension lead to different processes of institutionalization and characterize institutional entrepreneurship in this context.

\section{Research Design}

To explore the phenomenon of communication as a responsibility dimension, and its characteristics, we decided to utilize the methodological approach of qualitative comparative case study research. Case study inquiry enables us to collect detailed information across a wide range of dimensions about the particular cases and is usually fruitful for exploring the how and why of contemporary phenomena [30]. As the study is of an exploratory nature and embedded in discourse theoretical approaches, we followed the interpretive framework in social science research [31] and employed different qualitative methods of data collection and analyses. The aim of the study is not just to shed light on the corporate understanding of communication as a CSR dimension with regard to a sustainable development of the food system but also on how and why, in relation to the societal effects for institutionalization, it is actually (communicatively) performed.

\subsection{Research Site and Case Selection}

Following the ongoing debate on the crucial role of food production in sustainable development [3] and the dependence of modern society on industrial food systems to sustain, we selected producing and processing corporations of the food industry as an attractive research site. Germany is Europe's food and beverage market leader and hosts national and international corporations, operating in nearly every subsegment. Besides, in a European context, Germany is described as "frontrunner in the production and consumption of organic food products" [32] (p. 7), generally associated with more sustainable production conditions. Yet, the industry in Germany is particularly controversial and divisive. More than ninety percent of food corporations in Germany are small- and medium-sized enterprises, while the remaining seven percent are large international corporations [33], ranging from organic-pioneers to multinational food corporations. While corporations, solely producing and processing organic food, are mainly seen as ecopreneurs, aspiring to grow profitable and sustainable businesses while changing the world through working for improved social and environmental justice [34], multinational food corporations are perceived as making decisions based solely on profit margins and projected future growth $[35,36]$. Notwithstanding, both forms of corporations with their different organizational contexts are embedded in global and national sustainability agendas, emphasizing the critical role of businesses in sustainability processes and forcing them, either for coercive, mimetic, or normative 
reasons, to account for their sustainability endeavors for organizing the food system more sustainable. This development becomes visible by the increasing number of corporations, regardless of obligation, inter alia, publishing CSR reports, building up CSR sections on corporate websites, and devoting special articles to sustainability in corporate customer magazines [37,38].

To maximize the utility of information about the research object at stake and to obtain information about the significance of various organizational circumstances, we decided to conduct a multiple-case design and followed the selection strategy of "maximum variation cases" combined with "deviant cases" [39]. We selected one ecopreneur-like corporation of the German food industry, honored with multiple sustainability awards, as well as one of the world's leading multinational food corporation, proven to be highly susceptible to public criticism. The two cases vary in the dimensions of size, budget, form of organization, organizational history, and are at the same time somehow extreme cases regarding their targeted market sector and public perception. However, both cases operate in the German, as well as the international food sector, and their business is based on the production and processing of food. By comparing the two cases, we could illuminate contextual aspects influencing the phenomenon of communication as a CSR dimension occurring in assorted characteristics. The use of two cases helped us to identify distinctive features and numerous factors governing the perception and performance of responsibility through communication by exploring similarities and differences between the two extreme cases and enabled us to generalize, to some extent, about the wider food industry [40].

\subsection{Data Collection and Methods}

One strength of the case study approach is the ability to incorporate a variety of different types of data gathered using multiple data collection methods [40]. In order to gain the data of corporate awareness, perception, and accounts of their experiences with communication as responsibility dimension, we conducted eight semi-structured interviews with corporate representatives engaged in CSR and CSR communication of the two cases between February and May 2017. For an overview of the data corpus, see Table 1. In the case of the Ecopreneur the interviewees consisted of the corporate founder and director, the sustainability manager, and one corporate communication manager, while in the case of the Multinational two public affairs managers, two sustainability managers, and the head of nutrition were interviewed. We developed an interview guide in advance, aiming to encourage the corporate representatives to talk in depth about the corporate understanding of sustainability and responsibility in relation to the future of the food system. To allow for more profound comparison, the same interview guide was applied in each interview. The interview duration was approximately 43 to 136 min. Subsequently, the interviews were fully transcribed using MAXQDA 12 software (VERBI Software, Berlin, Germany), which was further deployed for data coding and analyzing.

Table 1. Data corpus.

\begin{tabular}{cccccc}
\hline \multirow{2}{*}{ Data Material } & \multicolumn{2}{c}{ Ecopreneur } & \multicolumn{2}{c}{ Multinational } & Time Range \\
\cline { 2 - 6 } & Amount & Scope & Amount & Scope & Year/s \\
\hline $\begin{array}{c}\text { in-depth interviews } \\
\text { with corporate } \\
\text { representatives }\end{array}$ & 3 & 255 min & 5 & 183 min & 2017 \\
\hline sustainability reports & 4 & 434 pages & 7 & 383 pages & $2007-2016$ \\
\hline websites & 1 & 108 webpages & 2 & 261 webpages & 2017 \\
\hline customer magazines & 3 & 69 pages & 5 & 179 pages & $2011-2017$ \\
\hline
\end{tabular}

To cover a wide range of corporations' public sustainability-related food communication and to explore how interpretations of sustainability are shaped and communicated, we collected readily accessible sustainability reports and customer magazines published in the period from 2007 to 2016, and 
corporate website disclosures related to CSR archived at the time of June 2017. We prepared the data of four sustainability reports for each case, three customer magazines from the Ecopreneur and five from the Multinational, as well as 108 webpages of the Ecopreneurs' and 261 webpages of the Multinationals' German websites for analysis and amalgamated them with the interview data in the research project file. The compiled data of documents of each case were considered as multiple organizational texts where they constitute the bodies of corporate sustainability-related food discourses [41].

\subsection{Data Analysis}

To increase knowledge about the understanding of communication as a CSR dimension in the context of the German food industry, we first undertook a detailed analysis of the phenomenon and tried to understand it from the corporate point of view. Therefore, we analyzed the interview transcripts of each case and inductively derived codes [42] that represent emerging concepts, ideas, themes, and categories with the corporate understanding of assuming responsibility through communication. We iteratively compared the emerging codes between the cases and identified commonalities and differences. As each code emerged more prominently, we reached theoretical saturation when we yielded seven codes, characterizing the meaning of communication as a CSR dimension, the main purpose, goals, challenges, strategies, corporate recommendations, and self-descriptions surrounding the concept. These characteristic features of communication as a CSR dimension were, then, analyzed again in order to reveal different roles of communication reflecting differences in the perception of CSR trough communication between the two cases.

In order to empirically examine the discursive performance associated with the perception of communication as a CSR dimension, we developed an integrated approach to organizational discourse, in so far as we started with investigating the emergence of issues related to sustainable food by inductively coding the interview transcripts and, then, connected them with the broader corporate discourse in the collected documents. We identified four overarching issues relating to sustainability from the corporate points of view cutting across both cases and re-read each case in order to identify how these issue-based fields were illustrated and interrelated in each case. In this way, we tried to tag the relevant sustainability discourses and sub-discourses of each corporation and capture all issue-based fields around which sustainability in relation to food is currently constructed. We analyzed the whole data corpus to understand and enrich the corporate specific interrelations of the issue-based fields and reveal field-specific genres used by the corporations. In order to understand how the corporations perceive communication as a CSR dimension in the issue-based fields, we compared our findings from the analysis of the interview data concerning different roles of communication with the associated roles of corporate discursive efforts in the fields. Then, we focused on the field of food quality as the data revealed that food quality is the main communicatively constructed responsibility object of the corporations in the context of sustainability and it is through the issue of "food quality" that the corporations try to engage in broader social discourses of a sustainable development of the food system. The data indicated the emergence of new interrelations between the issue-based fields, as well as change in the former understanding of food quality.

\section{Findings and Discussion}

The section is organized into three parts. The first part explores the general understanding of communication as a CSR dimension. The second part discusses different roles of food communication by assuming CSR through communication and demonstrates how corporations apply them and engage in issue-based fields in order to leverage the emergence of sustainable institutions in a broader social context. The third part discusses institutional entrepreneurship and related perceptions of communication as a CSR dimension that has become prominent in our data, as being the most important practices to institutional emergence or change for sustainability. 


\subsection{Communication as Responsibility Dimension for Sustainable Development of the Food System}

Social discussions about sustainability underline the uncertainty about the meaning of the term itself. The analysis of our data revealed that the corporations are generally averse to using the term "sustainability". They complain that the understanding of the term differs considerably depending on the context in use and comment on its inflationary usage leading to loss of significance. Scholars have already revealed that sustainable development means "different things to different people in different contexts" [43] (p. 129) and has been constructed in various discourses with wholly or partially mutually exclusive outcomes $[43,44]$. From the corporate point of view, this inconsistency is still one of the major challenges in moving forward in sustainable development.

"Not until all of us in society have a common understanding and act together, I believe it won't be possible to carry sustainability forward. As long as the issue is understood to be extremely different and is sometimes driven by different motivations, it will hardly ever give a clear picture on the consumer side". (Multinational, Public Affairs Manager 1)

It is widely perceived that people achieve a joint understanding through communication and, in terms of sustainability, a broad participation of relevant social actors in social discourses is indispensable to leverage institutionalization of shared patterns of interpretation, in turn promoting sustainable actions in the broader society [45].

"When looking at sustainability in macrosocial terms, there is also the question of finding a way to achieve more sustainability as a society as a whole, and we can only manage this by communicating about sustainability". (Ecopreneur, Sustainability Manager)

It seems that corporations are aware of this, as our data revealed that they understand communication as a dimension of CSR and as an obligation to engage in social sustainability-related negotiation processes in order to leverage a common understanding. However, this common understanding does not relate to the term" sustainability" itself, but rather relates to the shared responsibility of society in order to achieve sustainability. While both cases see this discursive engagement as a social obligation resulting from a corporation being part of society, the Ecopreneur additionally feels a moral obligation to communicate its perspective on sustainable food to enable its "green ideology" to disseminate. This is not surprising, as ecopreneurs generally have a strong commitment to the environment and build their businesses on the basis of their moral ethic and economic value. [46]. Nonetheless, the overall purpose of assuming CSR through communication for both is to define corporate possibilities for shaping a sustainable food system in communicative processes within society.

"As said before, we cannot manage sustainability through the corporation alone, but rather we see it as a cooperative task of many stakeholders, because the central question always raised is whether corporations can play any role at all in facilitating sustainability (.. ) where we engage in discussions. Where we take a stand, we are also saying, what our contribution on this occasion might be". (Multinational, Nutrition Manager)

While the pursued goals of assuming responsibility through communication in the context of a sustainable development of the food system differ slightly between the two cases, they utilize different communication strategies based on various understandings about the underlying role of communication to accomplish them, and engage differently in issue-based fields encompassing various social perspectives and discourses of sustainable food actions.

\subsection{Roles of Food Communication in Issue-Based Fields of Sustainable Food}

We identified five different roles of communication in our data, which partly overlap by assuming CSR through communication and that aggregate in their variations to two different conceptualizations of conceiving communication as a CSR dimension by comparison of the two cases (see Table 2). 
Table 2. Different roles of food communication in food industry's CSR.

\begin{tabular}{cc}
\hline & Communication as ... \\
\hline$\ldots$ a medium & to generate insights and knowledge \\
\hline$\ldots$ a purpose & to build and maintain relationship networks and partnerships \\
\hline$\ldots$ a process & to solve problems \\
\hline$\ldots$ a transmission medium & to transmit data, facts, messages and disclose achievements \\
\hline$\ldots$ an instrument of power & to enforce understandings of acting sustainably in other contexts \\
\hline
\end{tabular}

In this section, we are going to present these different roles of corporate food communication with respect to the issue-based fields around which sustainable food is constructed. According to Hoffman [7] (p. 352), the presence of an issue-based field can be analyzed by empirically observing three indicators, i.e., organizational interactions, shared information load, and awareness of being involved in common debates. By analyzing the interviews, we identified various issues around which sustainable food is constructed, which, for both cases, can be subsumed to four main issue-based fields at a given point of time. These fields deal with questions of food origin and manufacturing, food composition, food quality, and food consumption and can be understood as the four main issues through which corporations engage in discourses about the future of food within society [47]. As an empirical unit of analysis, a field indicates institutional processes that define and redefine the field over time. Shared interests and agendas represent stability mechanisms, while shifting power relations indicate change mechanisms [48].

Table 3 gives an overview of these issue-based fields with sub-issues, the main field membership defining interaction patterns through perceiving communication as responsibility dimension as well as the main identified corporate communication genres, for both cases.

The four issue-based fields subdivide into various sub-issues, which themselves can be broken down to various subordinated issues. In the issue-based field of food origin and manufacturing, for instance, the sub-issue of supply chain management could be further divided into issues of transparency, social and environmental security, regionality, etc. There are also factual overlaps of current sub-issues that interrelate and can affect different fields but are typically debated just in one of the issue-based fields. 
Table 3. Four main issue-based fields of corporate sustainable food discourse.

\begin{tabular}{|c|c|c|c|c|}
\hline \multirow{2}{*}{$\begin{array}{c}\text { Issue-based Fields of } \\
\text { Corporate Sustainable Food } \\
\text { Discourse } \\
\end{array}$} & \multirow{2}{*}{ Sub-issues } & \multicolumn{2}{|c|}{ Perception of Communication as Responsibility Dimension } & \multirow{2}{*}{ Corporate Genres } \\
\hline & & Ecopreneur & Multinational & \\
\hline Food origin and manufacturing & $\begin{array}{l}\text { business policy, employee } \\
\text { management, (organic) farming, } \\
\text { food waste, manufacturing } \\
\text { standards, supply chain } \\
\text { management }\end{array}$ & $\begin{array}{l}\text { communication as a medium } \\
\text { and purpose }\end{array}$ & $\begin{array}{l}\text { communication as an } \\
\text { instrument of power }\end{array}$ & $\begin{array}{c}\text { corporate brochures, corporate } \\
\text { websites, customer magazines, } \\
\text { face-to-face, management } \\
\text { guidelines, social media, } \\
\text { sustainability reports, press } \\
\text { work }\end{array}$ \\
\hline Food (product) composition & $\begin{array}{l}\text { additives, aromatization and } \\
\text { ingredients, product } \\
\text { reformulation, recent scandals }\end{array}$ & communication as a process & $\begin{array}{l}\text { communication as a } \\
\text { transmission medium }\end{array}$ & $\begin{array}{l}\text { corporate (service) websites, } \\
\text { customer magazines, product } \\
\text { communication }\end{array}$ \\
\hline $\begin{array}{c}\text { Food quality } \\
\text { (classic conception) }\end{array}$ & $\begin{array}{l}\text { food prices, food risks, product } \\
\text { safety, trust }\end{array}$ & communication as a process & $\begin{array}{l}\text { communication as a } \\
\text { transmission medium }\end{array}$ & $\begin{array}{l}\text { customer magazines, press } \\
\text { releases, product } \\
\text { communication }\end{array}$ \\
\hline Food consumption & $\begin{array}{c}\text { cooking skills, enjoyment, } \\
\text { food-related bodily } \\
\text { changes/diseases, food waste, } \\
\text { health, nutrition practices/ diets, } \\
\text { taste }\end{array}$ & communication as a purpose & communication as a medium & $\begin{array}{l}\text { corporate service websites, } \\
\text { customer magazines, } \\
\text { face-to-face, newsletters }\end{array}$ \\
\hline
\end{tabular}




\subsection{Food Quality As A Resource for Common Understanding Processes}

The Ecopreneur communicates sustainable food mainly as a matter of quality. Food quality is defined as the main responsibility object of the corporation for sustainable development of the food system. The Ecopreneur understands sustainable food quality principally as a matter of food origin and production and constructs its meaning of sustainable food around sub-issues relating to this field. As a corporation of the organic food industry, the Ecopreneur always traces sustainable food back to organic agriculture as the basis for further sustainable development of the food system.

"Well, in the area of food there is very much that relates to the topic of sustainability and various aspects interlock. Of course, healthy and good food belongs to this area, but also enjoyment and the pleasure of eating belongs to sustainability. In addition, equally, so do the social and ecological aspects, because the food that we eat is always grown by someone somewhere. That's where sustainability begins: that these people can make a good living, that they grow food under fair conditions, that they are able to produce good food. This is only possible by working ecologically, when the soils are machined reasonably well, and when there are reasonable conditions". (Ecopreneur, Sustainability Manager)

By utilizing communication mostly as a medium and purpose in this issue-based field, the Ecopreneur ensures only to connect to farmers, suppliers, and retailers that share these attitudes. Communication as a medium implies that communication serves as a vehicle to gain knowledge. Both cases use communication with stakeholders of society as a means to increase corporate knowledge and sensitization of social values and current issues, utilize feedback, pick up sustainability stimuli, and exchange perspectives on sustainable food. The Ecopreneur, in the field of food origin and manufacturing, based on the knowledge gained about the values of the other field actors and organizations through communication as a medium, then, decides about building an interest group in order to collectively produce sustainable food products according to the shared understanding of the group. By understanding communication as a purpose, corporations communicate to build up or stabilize relationships with other actors or organizations in the food system. Both corporations, to different extents, establish and engage in various communication networks and communicatively interact within these networks on a regular basis in order to maintain them.

In the classic conception of the issue-based field of food quality, based on sub-issues such as product safety and food risks, the Ecopreneur only engages in cases of media-raised food scandals, for example, regarding unwanted residues in food. Then, it perceives its responsibility through food communication by utilizing communication as a process where communication is understood as an ongoing process for the purpose of problem solving, for example, by connecting the food scandal issue to scientific discourses to leverage development of methodologies in order to prevent raw materials from being contaminated with undesired substances. The classic conception of the field of food quality, thus, plays a minor role in its communication, as "critical substances are not in use. And, by not using such substances, the likelihood of containing products decreases" (Ecopreneur, Corporate Communication Manager).

Additionally, both cases make use of the role of communication as a process by continually communicating within sustainability management systems to solve problems of food processing and production within the corporate structures. The Ecopreneur also utilizes this role of communication in the issue-based field of food origin and manufacturing to initiate processes of problem solving by other organizations and actors in the food system, for instance, by putting innovations on the market in order to stimulate discussions for further sustainable development in society. Thus, the Ecopreneur decides to use a specific sustainable packaging material even if the necessary structures for composting the material are not (yet) given in the public waste system, in order to raise awareness of more sustainable options of product packaging and to trigger processes of problem solving in other contexts of society related to the food system. Therefore, corporations have to emerge new fields or get access to relevant fields where common or opposite interests concerning these issues are contested and serve as coordinating mechanisms [48]. 
The Ecopreneur is aware of the necessity of communicating about food in society in larger terms and addresses multiple other actors and organizations, such as politicians, legislators, consumers, retailers, and farmers. The Ecopreneur, throughout the period analyzed, connects to these other social discourses via the common interface of "quality". The Ecopreneur builds its whole understanding of sustainable food within an enlarged framework of quality. This results in the issue-based field of food quality also encompassing the other issue-based fields, which as a whole can be described a sustainable food quality concept of the Ecopreneur (see Figure 1).

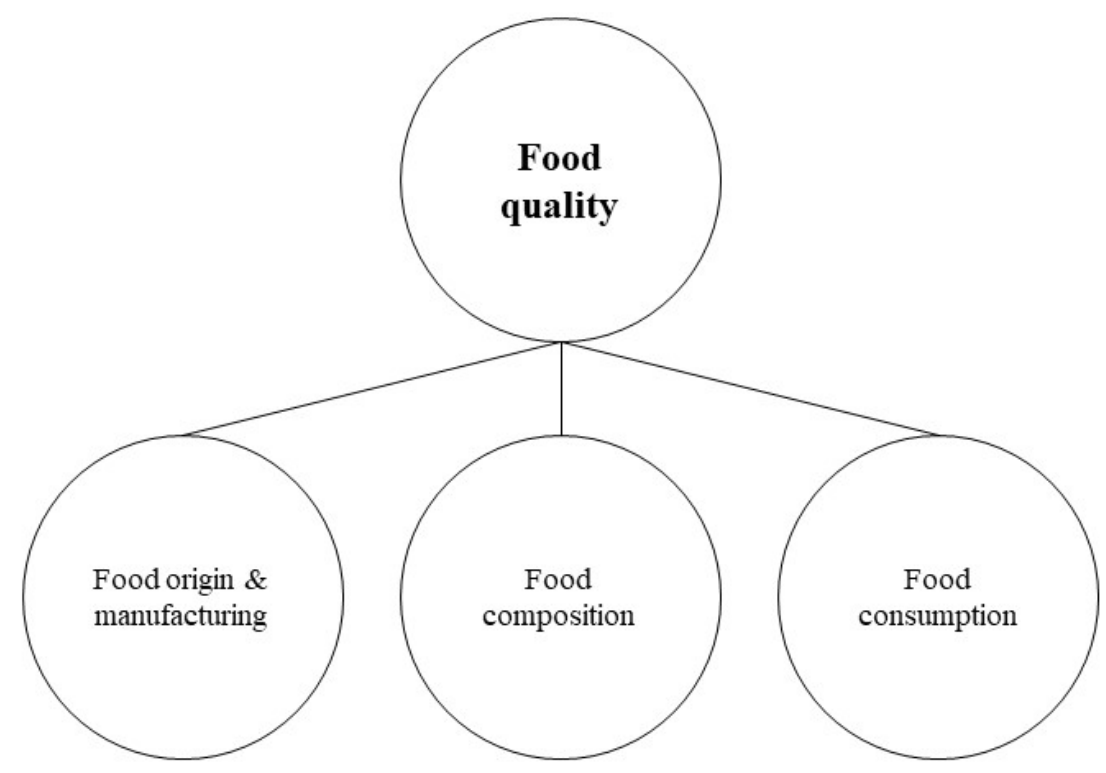

Figure 1. Ecopreneurs' configuration of the four issue-based fields of sustainable food quality.

The issue-based fields of food origin and manufacturing, food composition, and food consumption are vertically tied to the larger field of food quality as initially defined in the business policy of the Ecopreneur.

"High quality is the basis of our actions. (...) Our corporate approach, from the outset, connects high quality - and therefore also economic success - with ecological and social aspects". (Ecopreneur, Sustainability Report 2007)

The Ecopreneur utilizes "quality" as a connecting link to social discourses, to its environment, as well as to economic discourses. In communicative networks within the entire food value chain, quality is defined by interaction with or by the actors in question.

"To investigate ecological food and its impact on human health we co-initiated a scientific institution, where European scientists can connect with one other and exchange information. This institution deals especially with questions of new methodologies to determine the quality of ecological food". (Ecopreneur, Sustainability Report 2007)

Thereby, the Ecopreneur, through communication as a process, advantages sensemaking processes in other social contexts, but does not determine their specific meaning of sustainable food quality beforehand. This, in turn, leads to information processing in context-specific ways and, consequently, leads to perspectives and meanings of how sustainable food quality is understood and can be achieved in a context-specific way. Thereby, the Ecopreneur is aware of the specific functions of other social systems, actors, and organizations, and thus of the urgency to engage in broader social discourses, for example, by perceiving responsibility through communication as a purpose in order to engage with the political discourse. 
"The collaboration with politicians is naturally taken extremely seriously by our corporation, as we are aware that the political system creates the framework conditions for the economy. There, a healthy development must be enabled". (Ecopreneur, Website 2017)

Taken together, the communicative behavior of the Ecopreneur could be interpreted as part of a cultural practice, where corporate food communication is part of processes in society where meaningful contexts emerge, and problems are placed and solved within these contexts. In order to develop a deep understanding of the food system, the Ecopreneur is eager to understand different social perspectives in the food system.

The Multinational, until the year 2012, mainly adhered to the classic concept of food quality, understanding food quality primarily as a matter of product safety and food composition and utilizing communication predominately as a transmission medium to let its idea of food quality disseminate. In the field of food origin and manufacturing, the corporation uses communication as an instrument of power to ensure compliance with quality assurance measures along its value chain.

"And, for us, this is the expression of responsibility that we try to implement. If there is transparency, if we know which farmers and suppliers in which countries and with which plants and production steps form the supply chain, to really ensure that everyone complies with the guidelines that we set." (Multinational, CSR-Manager 2)

By seeing communication as an instrument of power, communication is deployed to accomplish specific goals or positions, often solely in the interest and specific perspective of the corporation. Global and corporate guidelines are used to transform supply chains into more sustainable ones by using these standards as binding contracts and as a basis for communication between the organization and the suppliers. In the case of the palm oil controversy around the year 2010, for instance, the Multinational claims to have successfully introduced industry-wide standards for responsible sourcing and thus "although we are so minute in palm oil, and we are still minute today, we commonly managed to turn around the industry" (Multinational, CSR-Manager 1).

Additionally, the Multinational uses communication as a medium and to a minor degree as a purpose in the field of food consumption in order to identify social expectations and perspectives towards food products and to adjust its sustainability strategy and topical focuses of corporate food communication. In these communicative networks, it is essential to demonstrate a willingness to work on sustainability issues and to derive issues from societal interests to prevent anticipated public criticism.

"Based on consumer surveys it arises that the basis of our corporate business is quality of food products. Our corporate brand attached to food products guarantees that consumption of these products is safe, it ensures that all regulations are properly obeyed and that the product complies with high quality standards". (Multinational, Sustainability Report 2006)

Following this, in 2012, the Multinational introduced a new quality program into its German operations. The introduction of this initiative, also entitled "quality means more", is seen, first, as an implication of utilizing communication as a medium in a more instrumental way, and second, as a reaction to the erosion of consumer confidence in the German food market, political demand for corporate sustainable actions, and increasing social expectations towards the role of corporations in processes of sustainable development [49]. This can be interpreted as a consequence of institutional change in the broader issue-based field of food quality where alternative perspectives on food quality have gained more presence and resulted in a redefinition of quality control in the organizational system of the Multinational [50].

"The holistic understanding of quality, as illustrated in our programme, encompasses nutritional aspects, such as e.g., the reformulation of recipes or knowledge transfer concerning food, but also sustainability issues in the supply chain". (Multinational, Sustainability Report 2015) 
Through the dynamics in the broader issue-based field of food quality and the assumption of communicative responsibility, the understanding of food quality is currently expanding and horizontally connecting to the issue-based field of food origin and manufacturing, as well as food composition (see Figure 2).

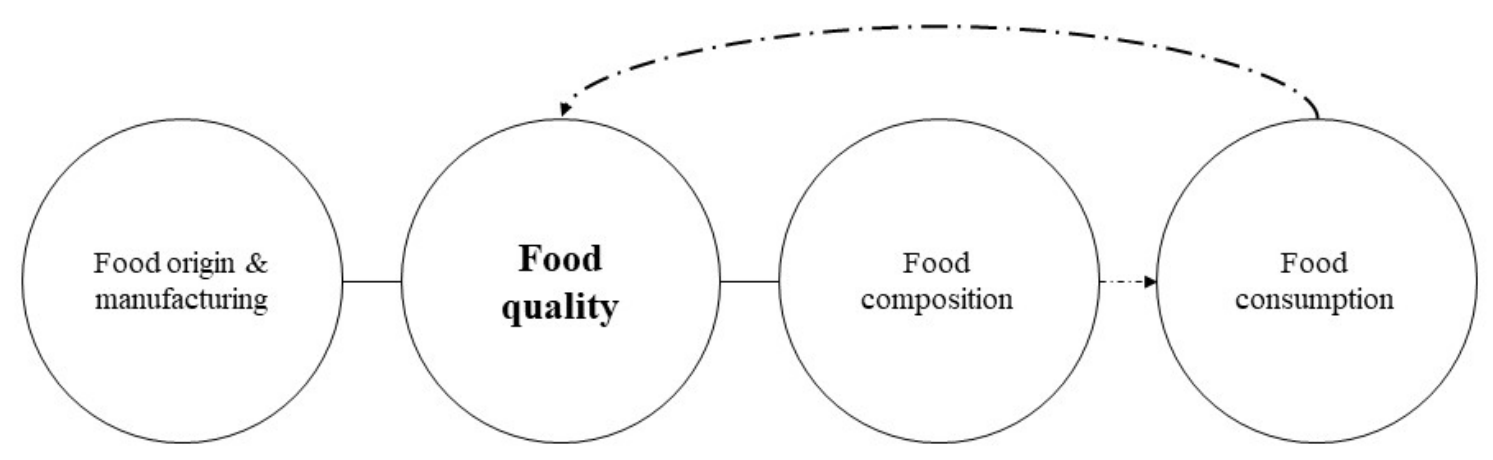

Figure 2. Multinationals' configuration of the four issue-based fields of sustainable food quality.

Thus, the issue-based field of food consumption fulfils two functions for the Multinational. First, it serves as a "data pool" and is coupled, through communication as a medium for the data gathering concerning shifting food habits and perspectives on sustainable food in society, to the newly emerging field of food quality (recurved dotted arrow). Second, it is an issue-based field isolated from the corporations' economic core business of producing food products and, instead, is targeted to a field of social communication ruled by a corporate scientifically based health logic.

This is due to the corporation also hosting its own various research and development institutes dealing with questions of food, health, and technology. Thus, in the field of food consumption, the Multinational connects to other social discourses, such as health, education, and science, mainly through the common interface of "health" as one aspect of sustainable food quality. As a result, corporate food communication in this issue-based field inevitably is not dedicated to collective sustainability aspects of food consumption that interrelate with the new perspectives on food quality, and thus with food origin and manufacturing, but rather is dedicated to individual health through consumption of the Multinationals food products and their composition according to the proposed evidence-based guidelines.

"Only if nutrition research directly collaborates with the food industry and recent research findings are translated for implementation into practice may the quality of the food products on the market and therefore, the nutrition of society, be improved sustainable". (Multinational, Website 2017)

By seeing communication as a transmission medium, where communication serves to transfer information, such as data, facts, and messages from the corporation to the broader public, the Multinational considers corporate food communication as "fact-based, validated" (Multinational, Public Affairs Manager 2) disclosure of corporate sustainability objectives and performances and as a transfer of knowledge concerning health, food, and sustainable consumption from the corporate scientific department towards society. This role of communication is in line with CSR communication strategies entitled "stakeholder-information strategy" [51] where communication content is given sense by the corporation solely, and the communication tasks include informing stakeholders about favorable corporate decisions and actions with regard to their role and understanding of sustainable food.

However, the traces of the research activities of the Multinational are also visible in the new emerging field of sustainable food quality. In corporate communications, it is still obvious that the Multinational sticks to its former conception of food composition being a matter of nutritional product quality and technological development and is eager to transfer this interpretation of food quality to the issue-based field of food consumption (rightwards dotted arrow). Simultaneously, it works on 
systematically connecting the issues of food composition more deeply into the new quality field by engaging with scientific systems through communication as a process in order to find a tool that is able to combine these two different perspectives of food quality.

"That is so to say, one the one hand we have the nutrition-physiological quality and on the other hand we have the sustainability quality of food products. This is something that is currently being developed in RED networks with different tools and scores (... ). How may we get this together?". (Multinational, Head of Nutrition)

The Multinational increases its impact on the supply chain and the spreading of its developed technologies on the food market by utilizing communication as a purpose and engaging in industry networks and communication coalitions in order to utilize corporate collective power and promote mandatory sustainability guidelines. Furthermore, the Multinational understands communication about sustainability in the food system as a kind of instrument for self-defense. In order to be "speech-enabled" the corporation tries to ensure transparency and introduces sustainability projects to be able to "walk the talk" [52] and show what the corporation is doing to transform the food system.

This form of communication of the side of the Multinational could also be interpreted as communication as system preservation, where the corporation as an organizational system constantly observes social discussions and seeks to identify irritations from the corporations' external environments that could become dangerous to the existence of the organizational system. Thus, assuming responsibility through food communication at the side of the Multinational in large parts can be seen as serving system preservation and self-interest of the corporation. Any aspects that are actually not socially discussed and do not fit the corporate perspective on sustainable food quality make no difference to the organizational system of the corporation, and thus have no information value for the Multinational.

\subsection{Sustainability-Oriented Transformation of the Institution of Food Quality and Institutional Entrepreneurship}

When comparing the different approaches of the two cases to their perception and performance of communication as a responsibility dimension, it becomes obvious that the structure and coherence of the individual organizational discourses relating to sustainable food vary between the two cases. Furthermore, the endeavors to engage in social discourses in the issue-based fields differ with respect to the perceived role of communication. While the discourse of the Ecopreneur regarding sustainable food quality seems more structured and coherent, it appears the Multinational is a powerful forerunner in the proliferation and development of (technological) standards. This leads us to the question as to which approaches that assume responsibility through communication are more successful in transforming existing institutions of the food system into more sustainable ones for future development of the food system.

In the model of discursive institutionalization [10], it is assumed that texts are more likely to become embedded in discourse and produce institutions when they originate from powerful actors, involve recognizable genres, and draw on existing discourses and texts. From the discursive perspective, an issue-based field is characterized by a shared set of social discourses that constitute institutions, "because there is not just one discourse but, rather, multiple sets of more or less structured discourses holding in place institutions that constrain and enable the behaviour of actors across the field" [10] (p. 647). Our two cases both seem to be aware that engaging and addressing these other social discourses with their inherent different perspectives on sustainability is crucial to initiate institutional change for sustainable food development.

"It requires strong partnerships and innovative business models with relevant actors along the whole value chain of food in order to continually extend a sustained quality". (Multinational, Website 2017) 
Additionally, both cases acknowledge the important role of corporations to participate in social discussions about the future of the food system and recognize, as well as appreciate, an expanded economic discourse of sustainable food.

"How should a debate lead to a result if not those, who have the largest frame for creation in their sphere of responsibility, participate in the discussion? Otherwise, we would have a naive and unworldly discussion carried by people that not at all are familiar with the issue and do not even know what is feasible". (Multinational, Public Affairs Manager 2)

Food communication, in the form of continuous interaction in multiple issue-based fields of sustainable food and with multiple context-specific outcomes, thus, can be seen to constitute institutions relevant to actions along the food system. The Multinational, by perceiving responsibility for sustainable food through communication mainly as an instrument of power, in the case of palm oil for instance, has successfully managed to create a new regulative institution of responsible sourcing and made it mandatory to various actors in the food value chain, thus, focusing on economic discourses of the food system to initiate institutional change.

"Most of all, our corporation wants to carry the dynamic of our initiative deeper into the food industry, in order to promote the significance of quality and standards (... ). Quality orientation will become the driver of growth for the whole food industry". (Multinational, Customer Magazine 2015)

The Multinational is aware that "key opinion leaders consider food corporations as being responsible to increase awareness on food quality" (Multinational, Website 2017) and intends to also nudge external change processes toward more sustainable food.

"We want to point out approaches as to what kind of behaviors in terms of health and environment of our society might also be acceptable in future (... ). We need a new food culture. We need a holistic understanding of food quality.". (Multinational, Customer Magazine 2012)

Thereby, the Multinational is striving to "become the leading corporation in all quality dimensions" (Multinational, Website 2017) and tries to achieve this by disseminating its perspective to society. However, institutions as common cognitive understanding are formed as meanings come to be shared and taken for granted [53]. Nevertheless, "joint cognitive understandings and meanings that emerge ( ... ) from communication are unlikely to be isomorphic with the original intentions of the multiple participants engaged in it" [9] (p. 14). In order for institutions to become shared across a broad society, it is crucial to engage with the relevant social systems through communicative interactions. This is to ensure meaning making at the system level, which forms the basis for follow-up communications that can lead to the production and reproduction of sustainable food institutions, in turn, then regulating related thoughts and actions of individuals and organizations. While the Multinational follows the logic of "we build quality", the Ecopreneur strives to follow the logic of "we commonly create quality".

In order to constitute a common reference frame and connectivity options for different actors and organizations from other social contexts, the sustainability-related food discourse of the Ecopreneur is clearly structured and coherently draws on the encompassing issue-based field of sustainable food quality. However, as the Ecopeneur states, "high quality alone is not enough - one has to communicate in an appropriate manner" (Ecopreneur, Sustainability Report 2007), and thus the corporation employs different approaches to communication. On the one hand, the Ecopreneur contextualizes its meaning of food quality in appropriate settings to maintain existing cultural-cognitive institutions in parts of society that already support this meaning and is aware of appropriate genres and settings to connect to these discourses.

"With all passion for community, we consider a membership as appropriate only if we are able to express ourselves, because, as part of the silent majority we never felt comfortable. We have a say, we lend an ear, and we hand down and take along. The greater goals, that all groups share, are organic 
production, quality and sustainability. And, as such, there is a unity in diversity". (Ecopreneur, Sustainability Report 2013)

On the other hand, the Ecopreneur aspires "to consistently set standards above legal standards and established norms" (Ecopreneur, Sustainability Report 2016). Therefore, the corporation perceives communication as part of cultural practice and connects to economic, as well as to other social discourses to be an "active co-creator of a positive and sustainable development of environment, society and economy" (Ecopreneur, Sustainability Report 2016). As texts "do not become institutionalized by themselves but only when they become understood in a particular way" [54] (p. 713), and have to be distributed and interpreted by other actors if they are to have organizing properties and the potential to become embedded in other discourses, the Ecopreneur is multilaterally interlinked with other actors of different social contexts. By identifying challenges of the economic system, suggesting solutions, presenting best practice examples, or simply exchanging perspectives on sustainability with actors representing other social contexts, the Ecopreneur interdiscursively connects while drawing on the issue-based field of food quality more generally.

Through active engagement in the complex and sometimes even contradictory processes of collective meaning making [55] the Ecopreneur manages to create new institutions or transforms existing ones in social discourses.

"This approach in the meantime meets with the approval and support of broad levels of the society so that leading test institutes have also started to extend their classical product quality tests with investigations of social and ecological aspects". (Ecopreneur, Sustainability Report 2007)

Thus, through leveraging sensemaking processes in other social contexts, the Ecopreneur manages to trigger redefinitions of food quality conceptions that iteratively move on and lead to further sensemaking processes in other contexts through actors and organizations that are engaged in the struggle over meaning in discourses of the issue-based field of food quality. The notion of quality itself changes in these discourses in a context- or system-specific way but hosts "some characteristics that cross cultural and geographical boundaries" [50] (p. 203). Thus, the shift in the classic conception of food quality of the Multinational and the destabilization of underlying institutions can be interpreted as a consequence of successful institutional entrepreneurial activity on behalf of the Ecopreneur. Genres, such as sustainability reports, are perceived as important media, as they open up the dialogue and provide interested society the opportunity to raise questions. However, it should be stressed that the Ecopreneur is also using this genre to disclose its perspective on sustainability and to explain how the corporation is dealing with the challenge of sustainable food production, while the major part of the industry still uses this genre to report on corporate actions to contribute to sustainable development [19]. Finally, the Ecopreneur considers face-to-face communication in relevant social discursive contexts as the most important genre to leverage institutional change, as it is the most effective and interactive way to engage directly in processes of social construction and exchange of people- and organization-centered perspectives on sustainability that underlie cognitive-cultural institutions [10].

Although the Ecopreneur describes itself as "extraordinary" and "extreme", while also being a "dwarf", the corporation is somehow aware of being an institutional entrepreneur. As the Ecopreneur states, "we enjoy a certain respect, we have extensive experience, and we are setting a good example, thus, others enjoy learning from us" (Ecopreneur, Corporate Communication Manager). Equally, the Multinational is aware that they are currently making progress but are still at the beginning and encapsulate themselves by self-imposed regulations. In the progress to more sustainable food, the Ecopreneur, in terms of social sustainability-related food communication, recommends making its own corporate sense out of ideas discussed in society while trying to understand other perspectives and keeping alive the discourse with multiple actors and organizations of different social contexts. This is in line with systemic approaches to communication that consider the function of specific social systems as relevant and acknowledge that representative actors of social systems act according to their difference-controlled perception [47]. 
However, in the macrosocial context, the Ecopreneur perceives itself as a flyspeck. Nevertheless, as the founder and manager of the Ecopreneur emphasized, "just many flyspecks make a large spot".

\section{Conclusions}

The intent of this paper has been to shed light on how corporations of the food industry understand and perceive communication as a responsibility dimension for a sustainable development of the food system and how corporate food communication may contribute to the maintenance, creation or disruption of institutions in turn guiding sustainable future actions in the food system. By emphasizing the importance of corporations engaging in social processes of understanding in order to leverage institutional change in the broader society, this study underlines corporate food communication as being more than a corporate service function to society or a matter of marketing communication. We revealed that perceived as responsibility dimension, corporate food communication could take on diverse roles with different potentials to leverage institutional change to trigger sustainability processes in the food system. By discussing institutional entrepreneurship and related communicative actions in the issue-based fields of sustainable food quality, we revealed the most successful discursive strategies of institutional creation and change emphasizing the critical aspect of dealing with and integrating social perspectives on sustainability.

\subsection{Implications}

The findings of this study contribute to several research strands. First, they expand the understanding of CSR and related communication to a social-constructivist perspective and underline the importance of corporate participation in social understanding processes relating to sustainability. This widens the perspective in CSR research from corporations being obliged to report on data concerning their responsible actions to corporations as institutional entrepreneurs for transformative changes in the food system. Because corporations are part of a complex society, in which meanings emerge through interaction, and different social actors and organizations refer to issues from different perspectives, only sections of problems are considered from each particular angle. Global sustainability challenges, and the development of a sustainable food system in particular, are typically ambivalent and highly complex and communicative interactions between the social actors involved are indispensable for developing a mutual understanding of what actions to take [24]. In this light, corporate CSR communication, and especially CSR action, that accompany face-to-face communications, such as stakeholder dialogues, participation in conferences, or activities in industry associations, gain relevance. Thus, the results of this study underline the potential of communication as an integral part of CSR for value creation and social learning processes for sustainability transformations [23,56]. By doing so, it expands the strategic perspective of CSR communication as a reactive corporate response to socially raised sustainability concerns to a meaning-centered approach. The results complement the existing theory on CSR by outlining discourse participation and related communicative actions as an additional dimension of the corporation's responsibility and as a vehicle for institutionalization processes for sustainable development.

Secondly, the findings of this study highlight the relevance of food quality as a common reference frame and an action guiding institution for sustainability in the food system. The meanings of how sustainable food quality is understood and achieved vary in context-specific ways but overall change in a more sustainability-oriented direction. The data shows that corporations carry out institutional work through communication and contribute to the change in meaning of the concept of quality that emerges as a communication resource for cross-system food-related discussions about sustainability. Thus, the results illustrate the significance of corporate sustainability-related food communication as a constructor of sustainability-relevant institutions. 


\subsection{Limitations and Future Research}

By unfolding implications for social understandings of sustainable food quality, this study highlights the need to further investigate the particularly prevailing understandings of food quality of other relevant actors and organizations of the food system, both upstream and downstream, for example, farmer organizations, food retailing corporations, and consumers, in order to make judgements over food system-wide institutionalization processes of similar meanings and sustainability transformations. For food communication research, it seems reasonable to further explore the potential of the concept of food quality to integrate various perspectives on sustainability in communicative understanding processes and to trigger a common understanding of sustainable actions for the future of the food system. Thus, our study is a starting point for connecting the research fields of CSR and food communication, and thus sheds more light on the need to recognize different social perspectives on sustainability for meaningful understanding processes. However, our study has several limitations to be addressed in future research. First, our study focusses on corporations of the food industry as relevant actors for the future of the food system. As social discourses of sustainable food are characterized by polyphony [57] and various social actors with their different perspectives on sustainability participate, there are more relevant research sites and organizations to investigate. Especially, corporations of other industry sectors (e.g., pharmacy) or science and health system organizations could be analyzed against the background of their dominance to shape meaning making processes in the issue-based fields of sustainable food quality. Second, our study is limited to a certain period, whereas acknowledging the dynamic view of field, issue emergence, growth, and decline is an ongoing process. Thus, the development of the issue-based field of sustainable food quality deserves greater attention in future research, in order to reflect on propositions of corporate progress in the transformation of the food system. Third, in this study only the corporate discourses were analyzed in order to make judgements over sustainability understandings and transitions in meaning. Therefore, it is not possible to make statements about the degree that the corporate "talk" actually represents the corporate actions. In addition, no statements can be made about the extent to which the constructed understandings of sustainability and sustainable food quality can really be ascribed as sustainable.

Author Contributions: Conceptualization, T.B.; methodology, T.B.; software, T.B.; formal analysis, T.B.; investigation, T.B.; resources, J.G.; data curation, T.B.; writing_original draft preparation, T.B.; writing-review and editing, T.B. and J.G.; visualization, T.B..; supervision, J.G.; All authors have read and agreed to the published version of the manuscript.

Funding: This research received no external funding.

Conflicts of Interest: The authors declare no conflict of interest.

\section{References}

1. Allen, T.; Prosperi, P. Modeling Sustainable Food Systems. Environ. Manag. 2016, 57, 956-975. [CrossRef] [PubMed]

2. Gamboa, G.; Kovacic, Z.; Di Masso, M.; Mingorría, S.; Gomiero, T.; Rivera-Ferré, M.; Giampietro, M. The Complexity of Food Systems: Defining Relevant Attributes and Indicators for the Evaluation of Food Supply Chains in Spain. Sustainability 2016, 8, 515. [CrossRef]

3. Oosterveer, P.; Sonnenfeld, D.A. Food, Globalization and Sustainability; Earthscan: New York, NY, USA, 2012.

4. Bartelmeß, T.; Godemann, J. Food communication of food industry corporations in the context of sustainability. A reconstructive analysis. Ernährungs Umsch. Int. 2019, 66, 100-108.

5. Schoeneborn, D.; Morsing, M.; Crane, A. Formative Perspectives on the Relation Between CSR Communication and CSR Practices: Pathways for Walking, Talking, and T(w)alking. Bus. Soc. 2019, 59, 5-33. [CrossRef]

6. Hardy, C. How institutions communicate; or how does communicating institutionalize? Manag. Commun. Q. 2011, 25, 191-199. [CrossRef]

7. Hoffman, A.J. Institutional evolution and change: Environmentalism and the U.S. chemical industry. Acad. Manag. J. 1999, 42, 351-371. 
8. Berger, P.L.; Luckmann, T. The Social Construction of Reality: A Treatise in the Sociology of Knowledge. Middlesex; Penguin Books: England, UK, 1966.

9. Cornelissen, J.P.; Durand, R.; Fiss, P.C.; Lammers, J.C.; Vaara, E. Putting communication front and center in institutional theory and analysis. Acad. Manag. Rev. 2015, 40, 10-27. [CrossRef]

10. Phillips, N.; Lawrence, T.B.; Hardy, C. Discourse and institutions. Acad. Manag. Rev. 2004, $29,635-652$. [CrossRef]

11. Christensen, L.T.; Cheney, G. Interrogating the communicative dimensions of corporate social responsibility. In The Handbook of Communication and Corporate Social Responsibility; Ihlen, Ø., Bartlett, J.L., May, S., Eds.; Wiley-Blackwell: Malsen, MA, USA, 2011; pp. 491-504.

12. Deblonde, M.; De Graaff, R.; Brom, F.R.A.N.S. An ethical toolkit for food companies: Reflections on its use. J. Agric. Environ. Ethics 2007, 20, 99-118. [CrossRef]

13. Herzig, C.; Schaltegger, S. Corporate sustainability reporting. In Sustainability Communication: Interdisciplinary Perspectives and Theoretical Foundations; Godemann, J., Michelsen, G., Eds.; Springer: Dordrecht, The Netherland, 2011; pp. 151-170.

14. Crane, A.; Glozer, S. Researching corporate social responsibility communication: Themes, opportunities and challenges. J. Manag. Stud. 2016, 53, 1223-1252. [CrossRef]

15. Caruana, R.; Crane, A. Constructing consumer responsibility: Exploring the role of corporate communications. Organ. Stud. 2008, 29, 1495-1519. [CrossRef]

16. Livesey, S.M. The discourse of the middle ground: Citizen Shell commits to sustainable development. Manag. Commun. Q. 2002, 15, 313-349. [CrossRef]

17. Du, S.; Bhattacharya, C.B.; Sen, S. Maximizing Business Returns to Corporate Social Responsibility (CSR): The Role of CSR Communication. Int. J. Manag. Rev. 2010, 12, 8-19. [CrossRef]

18. Schultz, F.; Castelló, I.; Morsing, M. The construction of corporate social responsibility in network societies: A communication view. J. Bus. Ethics 2013, 115, 681-692. [CrossRef]

19. Tench, R.; Sun, W.; Jones, B. (Eds.) Communicating Corporate Social Responsibility: Perspectives and Practice; Emerald: Bingley, UK, 2014.

20. Mauss, M. Die Gabe: Die Form und Funktion des Austauschs in archaischen Gesellschaften; Suhrkamp: Frankfurt am Main, Germany, 1968.

21. Godemann, J.; Bartelmeß, T. Communication of food and sustainability in relain to food communication research. Ernährungs Umsch. Int. 2017, 12, 188-194.

22. Munshi, D.; Kurian, P.A. Imagining Organizational Communication as Sustainable Citizenship. Manag. Commun. Q. 2014, 29, 153-159. [CrossRef]

23. Høvring, C.M. Corporate social responsibility as shared value creation: Toward a communicative approach. Corp. Commun. Int. J. 2017, 22, 239-256. [CrossRef]

24. Newig, J.; Schulz, D.; Fischer, D.; Hetze, K.; Laws, N.; Lüdecke, G.; Rieckmann, M. Communication Regarding Sustainability: Conceptual Perspectives and Exploration of Societal Subsystems. Sustainability 2013, 5, 2976-2990. [CrossRef]

25. Phillips, N.; Hardy, C. Discourse Analysis: Investigating Processes of Social Construction; SAGE: Thousand Oaks, CA, USA, 2002.

26. Wooten, M.; Hoffman, A.J. Organizational fields: Past, present and future. In The SAGE Handbook of Organizational Institutionalism; Greenwood, R., Oliver, C., Suddaby, R., Sahlin, K., Eds.; SAGE: London, UK, 2008; pp. 130-147.

27. Athanasopoulou, A.; Selsky, J.W. The social context of corporate social responsibility. Bus. Soc. 2012, 54, 322-364. [CrossRef]

28. Sandhu, S. Strategic communication: An institutional perspective. Int. J. Strategic Commun. 2009, 3, 72-92. [CrossRef]

29. Greenwood, R.; Oliver, C.; Suddaby, R.; Sahlin, K. (Eds.) The SAGE Handbook of Organizational Institutionalism; SAGE: London, UK, 2008.

30. Yin, R.K. Case Study Research: Design and Methods; SAGE: Los Angeles, CA, USA, 2014.

31. Bhattacharya, H. Interpretive research. In The Sage Encyclopedia of Qualitative Research Methods; Given, L.M., Ed.; SAGE: London, UK, 2008; pp. 464-467. 
32. MacDougall, W. The Food E Beverage Industry in Germany: Industry Overview; Germany Trade and Invest: Berlin, Germany, 2016.

33. Statista. Lebensmittelindustrie in Deutschland: Betriebe in der Lebensmittelindustrie in Deutschland nach Größenklassen 2015. Available online: https://de.statista.com/statistik/daten/studie/321346/umfrage/betriebein-der-lebensmittelindus-in-deutschland-nach-beschaeftigtengroessenklassen/ (accessed on 16 August 2019).

34. Indaco-Patters, S.; Fearon, C.; Nolan, C.; Warden, K. Micro-ecopreneurs and the UK food industry: Short-term fad or sustainable reality? Ind. Commer. Train. 2013, 45, 330-335. [CrossRef]

35. Kruchem, T. Am Tropf von Big Food: Wie die Lebensmittelkonzerne den Süden erobern und arme Menschen krank machen; Transcript: Bielefeld, Germany, 2017.

36. Smith, A.F. (Ed.) The Oxford Encyclopedia of Food and Drink in America; Oxford University Press: Oxford, UK, 2013.

37. Reilly, A.H.; Hynan, K.A. Corporate communication, sustainability, and social media: It's not easy (really) being green. Bus. Horiz. 2014, 57, 747-758. [CrossRef]

38. Valente, M. Corporate responsibility strategies for sustainability. In Corporate Social Responsibility: Strategy, Communication, Governance; Rasche, A., Morsing, M., Moon, J., Eds.; Cambridge University Press: Cambridge, UK, 2017; pp. 86-109.

39. Flyvbjerg, B. Case study. In The SAGE Handbook of Qualitative Research; Denzin, N.K., Lincoln, Y.S., Eds.; SAGE: Los Angeles, CA, USA, 2011; pp. 301-316.

40. Daymon, C.; Holloway, I. Qualitative Research Methods in Public Relations and Marketing Communications; Routledge: London, UK, 2011.

41. Heracleous, L.T. Interpretivist approaches to organizational discourse. In The SAGE Handbook of Organizational Discourse; Grant, D., Hardy, S., Oswick, C., Putnam, L.L., Eds.; SAGE: London, UK, 2004; pp. 175-192.

42. Benaquisto, L. Codes and coding. In The SAGE Encyclopedia of Qualitative Research Methods; Given, L., Ed.; SAGE: Thousand Oaks, CA, USA, 2008; pp. 85-88.

43. Bebbington, J. Sustainable development: A review of the international development, business and accounting literature. Account. Forum 2001, 25, 128-157. [CrossRef]

44. Eakin, H.; Connors, J.P.; Wharton, C.; Bertmann, F.; Xiong, A.; Stoltzfus, J. Identifying attributes of food system sustainability: Emerging themes and consensus. Agric. Hum. Values 2017, 34, 757-773. [CrossRef]

45. Godemann, J.; Michelsen, G. Sustainability Communication - An Introduction. In Sustainability Communication: Interdisciplinary Perspectives and Theoretical Foundations; Godemann, J., Michelsen, G., Eds.; Springer: Dordrecht, The Netherland, 2011; pp. 3-11.

46. Walton, S.; Kirkwood, J. Making greening matter!: Ecopreneurs commitment to environmental concerns and economic success. Acad. Manag. Proc. 2009, 2009, 1-6. [CrossRef]

47. Melde, T. Nachhaltige Entwicklung durch Semantik, Governance und Management; Springer: Wiesbaden, Germany, 2012.

48. Raffaelli, R.; Glynn, M.A.; Strandgaard Pedersen, J. Towards a General Theory of the Institutional Field; Harvard Business School: Boston, MA, USA, 2013.

49. Van Kleef, E.; Ueland, Ø.; Theodoridis, G.; Rowe, G.; Pfenning, U.; Houghton, J.; van Dijk, H.; Chryssochoidis, G.; Frewer, L. Food risk management quality: Consumer evaluations of past and emerging food safety incidents. Health Risk Soc. 2009, 11, 137-163. [CrossRef]

50. Mason, P.; Lang, T. Sustainable Diets: How Ecological Nutrition Can Transform Consumption and the Food System; Earthscan: Oxon, UK, 2017.

51. Morsing, M.; Schultz, M. Corporate social responsibility communication: Stakeholder information, response and involvement strategies. Bus. Ethics A Eur. Rev. 2006, 15, 323-338. [CrossRef]

52. Tewari, R.; Dave, D. Corporate social responsibility: Communication through sustainability reports by Indian and multinational companies. Glob. Bus. Rev. 2012, 13, 393-405. [CrossRef]

53. Scott, W.R. Institutions and Organizations: Ideas, Interests and Identities; SAGE: Los Angeles, CA, USA, 2014.

54. Phillips, N.; Malhotra, N. Taking social construction seriously: Extending the discursive approach in institutional theory. In The SAGE Handbook of Organizational Institutionalism; Greenwood, R., Oliver, C., Suddaby, R., Sahlin, K., Eds.; SAGE: London, UK, 2008; pp. 702-720.

55. Hardy, C.; Maguire, S. Institutional Entrepreneurship. In The SAGE Handbook of Organizational Institutionalism; Greenwood, R., Oliver, C., Suddaby, R., Sahlin, K., Eds.; SAGE: London, UK, 2008; pp. 198-217. 
56. Brown, A.D.; Colville, I.; Pye, A. Making Sense of Sensemaking in Organization Studies. Organ. Stud. 2014, 36, 265-277. [CrossRef]

57. Calefato, P.; La Fortuna, L.; Scelzi, R. Food-ography: Food and new media. Semiotica 2016, 2016, 371-388. [CrossRef]

(c)

(C) 2020 by the authors. Licensee MDPI, Basel, Switzerland. This article is an open access article distributed under the terms and conditions of the Creative Commons Attribution (CC BY) license (http://creativecommons.org/licenses/by/4.0/). 